\title{
CIUDADANÍA PRECARIA: HACIA UNA DEFINICIÓN CONCEPTUAL PARA LA CARACTERIZACIÓN DE LOS PROCESOS MIGRATORIOS CONTEMPORÁNEOS*
}

\section{Precarious Citizenship: Towards a conceptual definition for the characterization of contemporary migratory processes}

Carlos Durán-Migliardi

Universidad Católica SilvaHenríquez, Santiago de Chile**

Luis Eduardo Thayer-Correa

Universidad Católica SilvaHenríquez, Santiago de Chile***

Recepción: 22/11/2019. Aceptación: 11/12/2019

DOI: http://dx.doi.org/10.21017/Rev.Repub.2020.v28.a78

\section{RESUMEN}

El objetivo de este trabajo es proponer una definición conceptual de la categoría "ciudadanía precaria" que permita aportar al conocimiento sistemático de las modalidades de incorporación/exclusión de los ciudadanos y ciudadanas migrantes en el contexto contemporáneo. A partir de la descripción de la naturaleza nominativa de esta definición, el artículo propone la construcción de un criterio operativo de conceptualización de la "ciudadanía migrante" en base a la distinción entre sus dimensiones normativas, políticas e interactivas.

Palabras clave: Ciudadanía, precariedad, migración, concepto, nominación.

\section{ABSTRACT}

The objective of this work is to propose a conceptual definition of the category "precarious citizenship" that allows to contribute to the systematic knowledge

* Este artículo fue realizado en el marco del proyecto FONDECYT regular N. 1170479.

** Investigador en procesos políticos de la historia reciente. Doctor en Investigación en ciencias sociales con mención en ciencia política FLACSO México. Investigador titular del Centro de Investigación en Ciencias Sociales y Juventud, Universidad Católica Silva Henríquez. Santiago, Chile. Correo electrónico: cduranm@ucsh.cl.

*** Investigador especialista en migración. Doctor en sociología Universidad Complutense de Madrid, España. Investigador titular Centro de Investigación en Ciencias Sociales y Juventud, Universidad Católica Silva Henríquez. Santiago, Chile. Correo electrónico: lthayer@ucsh.cl. 
of the modalities of incorporation/exclusion of migrant citizens in the contemporary context. From the description of the nominative nature of this definition, the article proposes the construction of an operational criterion of conceptualization of "migrant citizenship" based on the distinction between its normative, political and interactive dimensions.

Key words: Citizenship, Precariousness, Migration, Concept, Nomination.

\section{INTRODUCCIÓN}

Hace casi dos décadas, Huntington (2004) advertía acerca de las consecuencias de la progresiva ampliación del status ciudadano hacia conglomerados cada vez más amplios de individuos, un fenómeno ocasionado en gran medida como efecto de la intensificación de los flujos migratorios y que, desde su perspectiva, constituía un fenómeno altamente problemático. En sus palabras (p. 252): “A finales del siglo XX [...] el concepto de ciudadanía nacional recibió una serie de envites diversos que fueron reduciendo los requisitos necesarios para adquirir el estatus de ciudadano y acabaron por mermar considerablemente la distinción entre los derechos y responsabilidades de los ciudadanos y los de los no ciudadanos. Tales fenómenos han sido legitimados aludiendo a los acuerdos internacionales sobre derechos humanos y al argumento de que la ciudadanía no es un producto de la nación, sino que es algo inherente al individuo. El vínculo entre ciudadanía y nación se ha roto, con lo que se ha debilitado [...] el orden nacional de la ciudadanía".

Un par de siglos antes, J. S. Mill sostenía la naturaleza inviable de los estados plurinacionales, argumentando que la relación vinculante entre ciudadanía y pertenencia nacional constituía un imperativo necesario de defender aun a costa de la coerción de las minorías o la reconfiguración de las fronteras nacionales, en caso de ser necesario. Y es que, Según Mill (1994, p. 182), “[1]as instituciones libres son casi imposibles en un país compuesto de nacionalidades diferentes, en un pueblo donde no hay lazos de unión, sobre todo si ese pueblo lee y habla distintos idiomas. No puede producirse en tales circunstancias la opinión pública indispensable para la obra del gobierno representativo".

Siglos de distancia y un mismo vínculo que liga la categoría de ciudadanía a una condición que, como la pertenencia nacional, expresa un atributo esencialmente "azaroso" pero que, en el marco de la modernidad occidental, ha asumido un lugar central tanto en la constitución de la idea misma de comunidad política como en el condicionamiento "del conjunto de oportunidades que cada cual puede disfrutar en la vida (Velasco, 2016, p. 15). Una centralidad que, con fenómenos contemporáneos tales como la reemergencia de los nacionalismos, 
el incremento de las dinámicas migratorias y la desnacionalización de las dinámicas económicas, reclama insistentemente su tematización ya sea para anunciar su superación definitiva, ya sea para declarar su persistencia y necesidad. El incremento de los procesos migratorios a escala global, claro está, ha reimpulsado estos tradicionales debates en torno a los alcances, límites y naturaleza específica de los procesos de incorporación, inclusión y/o integración del cada vez más significativo número de extranjeros que se avecindan en otro país. Un debate que, en su sola enunciación, da cuenta de la condición diferenciada de los ciudadanos y ciudadanas migrantes respecto a la población nativa, asumida como depositaria plena del conjunto de derechos dados por su pertenencia a la comunidad política-nacional.

Bajo el telón de fondo de estos debates y consideraciones -los que por cierto tienen una larga data en la teoría, las ciencias sociales y el campo de los estudios migratorios en lo específico- es que nos interesa discutir precisamente en torno a las formas de abordaje de la relación entre la condición migrante y el estatuto ciudadano. Nuestro objetivo es proponer una definición conceptual del término "ciudadanía precaria" que permita caracterizar las diversas formas que adquieren los procesos de incorporación/exclusión de la población migrante a la vez que diferenciarlos de las dinámicas regulares de producción de la ciudadanía. Se trata, en definitiva, de proponer una solución conceptual al problema del carácter parcialmente indeterminado del status migrante y del uso incompleto y fragmentario que, según nuestro criterio, ha presentado hasta ahora la definición "ciudadanía precaria".

Para cumplir con este objetivo, en la primera parte de este ensayo ofreceremos una breve definición del concepto de ciudadanía para, en la segunda parte, exponer los usos que la noción de "ciudadanía precaria" ha adquirido en el campo de las ciencias sociales. En la tercera parte daremos cuenta de la relación entre la pertenencia nacional, el status ciudadano y los procesos migratorios, argumentando en torno a la especial pertinencia que para la caracterización de esta relación adquiere la definición "ciudadanía precaria".

En la cuarta y última parte de este trabajo intentaremos exponer las insuficiencias conceptuales de la definición "ciudadanía precaria" para luego proponer una definición conceptual que permita su uso efectivo para la comprensión de los procesos contemporáneos de incorporación/exclusión de la población migrante.

\section{CIUDADANÍA}

Más allá de la inabordable producción investigativa y los múltiples debates existentes en torno a la naturaleza del concepto de ciudadanía, existen algunos ele- 
mentos que emergen de modo recurrente a la hora de determinar su especificidad. Observemos en este sentido algunas definiciones: "La ciudadanía puede ser definida como un conjunto de derechos y deberes que hacen del individuo miembro de una comunidad política, a la vez que lo ubican en un lugar determinado dentro de la organización política, y que, finalmente, inducen un conjunto de cualidades morales (valores) que orientan su actuación en el mundo público" (Bobes, 2007, p. 50); “[la ciudadanía consiste en la] percepción estatal de la persona" (Zapata, 2001, p. 7); "El ciudadano es el hombre incitado a tomar en cuenta el bien público y que recibe a cambio la protección pública para sus derechos" (Raynaud y Rial, p. 94); "la ciudadanía es el modo de pertenencia de los individuos a una comunidad política" (Rubio, 2007, p. 66).

Como podemos observar, tres son los elementos que están presentes en todas estas definiciones: 1) derechos y deberes encarnados en 2) un individuo que pertenece a una 3) comunidad política. Ahora bien, ¿de qué modo se relacionan estos componentes? Si la condición ciudadana es asumida como descriptor de la relación entre el ser individual y el orden jurídico-político en el cual éste se inserta, ¿cómo se determinan los límites de dicha condición?; ¿cómo se establece la frontera entre la dimensión pública del ciudadano y la dimensión privada del individuo?; ¿de qué modo se establece la relación entre derechos y deberes del ciudadano?; ¿cuál es la frontera que permite distinguir entre ciudadanos y no ciudadanos?

Las preguntas arriba expuestas han dado paso a un debate que ha derivado en definiciones múltiples y muchas veces contradictorias en torno a la comprensión de los alcances y límites de la condición ciudadana. Y es que, tal y como plantea Bovero (2002, p.118) "[...] la definición del contenido de la ciudadanía es, precisamente, problemática y controvertida: muchos estudiosos discuten entre sí para establecer cuáles son los derechos que caracterizan al status de ciudadano; qué relación hay entre estos, o bien si entre los distintos tipos de derechos del ciudadano subsiste un vínculo de integración e implicación recíproca, o bien si existen tensiones o aporías, o incluso contradicciones entre ellos".

Esta naturaleza múltiple y polémica de contenidos arropados bajo esta categoría puede reducirse a una dualidad que acompañará de manera permanente el devenir de sus concepciones: por una parte, ciudadano entendido como encarnación de derechos garantizados por el Estado y que, a la vez, determinan una limitación del poder público; por otra, como agente portador de derechos políticos que lo dotan de capacidad para la intervención activa en la producción y reproducción del poder público.

En términos generales, esta dualidad puede verse retratada en la distancia que Macpherson (1997, p. 47) refiere entre el liberalismo utilitarista, según el 
cual “[...] el sistema político debía producir gobiernos que establecieran y protegieran una sociedad de mercado libre, y al mismo tiempo protegieran a los ciudadanos contra la rapacidad de los gobiernos", y desarrollos posteriores que comienzan a sostener que el sistema político democrático, más allá del resguardo de los derechos individuales, contiene la virtud de dar "[...] a todos los ciudadanos un interés directo en los actos de gobierno, y un incentivo para participar activamente, por lo menos hasta el punto de votar por el gobierno o contra él, y [...] para informarse y formar sus opiniones en conversaciones con otros" (1997, p. 66).

Desde una perspectiva distinta, Held (1992) entiende esta dualidad en la forma de una distinción entre modelos de democracia - "protectora" y "desarrollista" - que conviven de modo permanente al interior de la tradición liberal, modelos que configuran expresiones "asistidas" y "emancipadas" de la ciudadanía, respectivamente. Similar es el balance que ofrece Norbert Lechner, para quien existe una concepción de la ciudadanía que, siendo más afín a los principios del "individualismo posesivo", entiende que la relación entre el orden político y el individuo-ciudadano ha de contar simplemente con el atributo de que el primero asegure la capacidad libre de agencia del segundo, mientras que existen otras visiones más expansivas de la ciudadanía, según las cuales la capacidad de agencia ha de vincularse estrechamente con la capacidad de intervención del ciudadano en los asuntos públicos.

Bobes (2004, pp. 16-24), por último, encuentra una serie de dicotomías que permanentemente tensionan y dificultan la producción de un contenido unívoco consensuado para este concepto. Es así como la ciudadanía se encontrará sistemáticamente en el medio de la disputa entre el modelo británico de la "ciudadanía propietaria" y el modelo francés de la "ciudadanía igualitaria"; entre la "visión radical roussoniana" y la "visión conservadora"; entre la "ciudadanía militante" y la "ciudadanía civil"; entre la ciudadanía como "status" y la ciudadanía como "práctica"; entre el énfasis en los "derechos" y el acento en los "deberes"; entre la ciudadanía "activa" y la ciudadanía "pasiva".

En síntesis, ya sea que se entienda al ciudadano como un depositario de derechos inalienables a ser resguardados por el Estado, como un agente político activo o como una combinación entre ambas concepciones, la ciudadanía constituye en última instancia el indicador de la presencia de un terreno político común en el que individuos aislados trascienden su singularidad para pasar a habitar un espacio homogéneo. En su condición de portador de derechos inalienables a ser resguardados por el Estado, el status ciudadano se traduce así en una expresión de la pertenencia del individuo a una comunidad que lo configura en tanto sujeto político y que lo habilita, por consecuencia, al ejercicio de una práctica reconocida y garantizada estatalmente. 


\section{CIUDADANÍA PRECARIA}

Desde que a mediados del siglo XIX Marx abordó el problema de los Derechos del hombre y del ciudadano evidenciando la distancia entre la emancipación política y la emancipación humana, la pregunta por las formas desiguales en que se ejerce la condición ciudadana ha sido una constante en el pensamiento social y político. De modos distintos, resulta transversalmente reconocido en el campo de las ciencias sociales el hecho que el ejercicio de la ciudadanía suele no ser idéntico a su reconocimiento formal, y que las posibilidades de ser parte de una comunidad política no han dependido solo de la dimensión jurídica o de la pertenencia nacional, sino que también de condiciones que trascienden a la ficción homogeneizante de la pertenencia a una comunidad política de iguales. Ocurre, en este sentido, que "la espacialidad política-institucional de los Estados-Nación no es homogénea ni completa para el conjunto del territorio y la población [...] posee topografías diferenciales e irregulares, contando en casos, con agujeros o vacíos de institucionalidad estatal donde territorios, poblaciones o grupos no son objetos de intervención de parte de aquel en cuestiones de protección social, infraestructura, recursos judiciales o seguridad" (Molina, 2014, pp. 92).

Como resultado de esto es que, a lo largo de la deriva moderna, se ha hecho evidente la presencia de formas desiguales de acceso a los derechos ciudadanos, formas que han incluido conflictos de diverso tipo, luchas sociales y transformaciones políticas que han derivado en la extensión del marco de derechos ciudadanos y en la alteración del universo de quienes demandan su derecho de pertenencia a la comunidad.

La historia de la ciudadanía moderna ha sido y continúa siendo, en este sentido, el escenario en que la expansión de los derechos de las mujeres, de los trabajadores, de las minorías y mayorías raciales, de las diversidades étnicas y de los excluidos de todo tipo ha modificado permanentemente sus contornos, expandiendo sus alcances y profundizando el marco de derechos que la define. Un proceso inacabado de extensiones, regresiones y modificaciones que permiten entender a la ciudadanía como un nombre en permanente disputa, cuyas fronteras y dinámicas de reconocimiento y exclusión, de incorporación y cierre se encuentran en constante proceso de reconfiguración. Por ello es que, ineludiblemente, "las presiones por la expansión de los derechos ciudadanos que emergen (o dejan de emerger) desde la sociedad civil, y cómo esas presiones son sobrellevadas por el Estado, son fundamentales para cualquier teoría causal de la ciudadanía [...] la ciudadanía refleja qué grupos participan en su construcción social y cómo lo hacen" (Oxhorn, 2014, p. 270)

Como parte de estos debates, durante el último tiempo ha comenzado a volverse común el uso de la categoría de "ciudadanía precaria" para hacer refe- 
rencia justamente a una modalidad específica de ejercicio de la ciudadanía que, con la profundización de fenómenos tales como la globalización, la crisis de los estados-nación, el agotamiento de las formas democráticas y la expansión de la soberanía de los mercados en desmedro de las comunidades, se caracterizaría por su limitación, parcialidad y/o condicionalidad. En otros términos, por su incorporación "precaria" a la comunidad de derechos y su consecuente ubicación en una condición que en definitiva "impide el desarrollo integral y participativo a los ciudadanos que la sufren" (Moreno, 2000, p. 14).

Pues bien, ¿cuáles son las características que definen esta condición precaria de la ciudadanía y los criterios posibles de utilizar para determinar su especificidad?; ¿contiene esta noción un valor heurístico para el estudio y caracterización de los procesos de incorporación de la población migrante?; ¿cuál es la diferencia que los distintos usos de esta definición proponen respecto a las definiciones convencionales de la ciudadanía?

Como consecuencia de la revisión de los diversos usos de la definición ciudadanía precaria es posible señalar dos cuestiones: en primer lugar, que las alusiones a dicho significante se caracterizan por la presencia de definiciones indiciarias, incompletas y/o fragmentarias que, sin embargo expresan la representación efectiva de un fenómeno de naturaleza distinta a la de la simple exclusión ciudadana. En segundo lugar, que el conjunto de referencias observadas alude a la presencia de un fenómeno que, trascendente a la dimensión puramente jurídica de la ciudadanía, es posible de ser identificada con un contexto epocal asociado a las recientes transformaciones del capitalismo contemporáneo.

En relación a los atributos con los que se asocia a la noción de ciudadanía precaria, cabe señalar que las referencias observadas se caracterizan por aludir a tres aspectos que producirían dicha condición. En primer lugar, la inexistencia o debilidad de una institucionalidad/legalidad capaz de garantizar el ejercicio continuo de determinados derechos ciudadanos. La existencia de un Estado sin capacidades institucionales para la incorporación de la totalidad de sus ciudadanos a la comunidad política de derechos, en el que "la ley no tiene vigencia ni se aplica" (Vite, 2012, p. 160) y en donde no se manifiesta la intención efectiva de intervenir sobre la facticidad de las inequidades, desigualdades o bloqueos a la inclusión de determinados ciudadanos y ciudadanas, se traduce según este criterio en precariedades que imposibilitan la incorporación de determinados colectivos al ejercicio efectivo de la ciudadanía.

En una segunda mirada, la condición ciudadana precaria se asociaría a un estado de "intermitencia", "discontinuidad" o derechamente "ausencia" de condiciones de ejercicio de los derechos ciudadanos por parte de determinados individuos o colectivos sociales. Dicha condición operaría con independencia a 
la formalización o reconocimiento de derechos por parte del Estado respectivo, y se asociaría más bien con déficits al nivel de la implementación efectiva de dichos derechos y a las formas de inclusión social. Es decir, correspondería a la "dificultad de algunos sectores de ciudadanos para tener acceso a la justicia y a la protección que las leyes confieren" (Celorio, 2017, p. 20). Más que falta de reconocimiento jurídico, en definitiva, esta dimensión de la precariedad se manifiesta en la forma de ausencia o debilidad en el nivel de las políticas estatales necesarias para el ejercicio efectivo de los derechos de los grupos ciudadanos ubicados en una posición desventajosa.

En tercer lugar, la condición precaria se vincularía también con la ausencia de un auto-reconocimiento de la condición de sujetos portadores de derechos por parte de los mismos ciudadanos y ciudadanas afectadas por el acceso desigual a la comunidad. Es decir, una condición según la cual un determinado grupo de individuos no se reconoce a sí mismos como poseedor de un cuerpo de derechos ni como miembros plenos de una comunidad política, precarizando aún más su condición. En un sentido político, así, ciudadanos precarios son aquellos que "no mencionan ni mucho menos manejan el tema de la participación [...] en la arena política, o sea, la participación del ciudadano organizado capaz de constituir un contrapeso del poder gobernante. Por lo mismo, su propia práctica de ciudadanía es precaria [pues] parecen ignorar que la fuerza de la democracia reside en la voluntad de los ciudadanos de actuar de manera responsable en la vida pública" (Baños, 2015, p.115).

Más que como un efecto intrínseco a los ciudadanos afectados por la condición precaria, esta ausencia de auto-reconocimiento de su condición de sujetos políticos opera naturalmente como efecto del marco de las interacciones sociales que caracterizan a determinados colectivos ubicados en una posición de subordinación, exclusión o dependencia.

En definitiva, las definiciones asociadas a la noción de ciudadanía precaria se vinculan con la caracterización de determinados agrupamientos sociales en tanto afectados por una condición de 1) acceso limitado al ejercicio de sus derechos ciudadanos, 2) inexistencia de una institucionalidad capaz de garantizar su participación en la comunidad de derechos y 3) ausencia de auto-reconocimiento de su condición de sujetos de derechos. Ya sea que se trate de grupos socioeconómicamente vulnerables, de miembros de las diversas expresiones de la diversidad sexual, personas afectadas por algún tipo de discapacidad funcional, partícipes de expresiones culturales subalternas, identidades culturales alejadas de la norma, o simplemente de colectivos juveniles afectados por el adulto-centrismo, la condición ciudadana precaria operaría en la medida en que los tres atributos arriba señalados se expresen en mayor o menor medida, restringiendo el ejercicio pleno de la ciudadanía. 
Pero la referencia a estos atributos no constituye el único componente posible de rastrear en los usos de la noción de ciudadanía precaria. Junto a estos, se observan recurrentes referencias -más o menos explícitas- a la inscripción de la noción en un contexto sustancialmente distinto al de la deriva típicamente moderna caracterizada -como más arriba lo señaláramos- por la expansión y profundización progresiva del status ciudadano. La condición precaria, en este sentido, contendría una diferencia cualitativa respecto a las formas típicamente modernas de ejercicio incompleto de la ciudadanía: en este caso, se trataría ya no de una condición transitoria sino que de un status permanente generado por transformaciones de alcance epocal que se traducirían en la gestación de formas estructuralmente incompletas de la ciudadanía que, en su propia constitución, bloquean el tránsito hacia la incorporación plena de los ciudadanos afectados por dicha condición.

En relación a esto, identificamos tres criterios de caracterización de la inscripción contextual de la ciudadanía precaria: 1) la profundización de los procesos de des-democratización, 2) la crisis de la economía capitalista del bienestar y el surgimiento de la forma económica post-fordista y 3) la consolidación del estado de excepción como una forma estable de producción de dinámicas de inclusión y exclusión social.

Sobre el primer criterio, el contexto de des-democratización es referido como parte de un marco histórico en que, como parte de fenómenos vinculados a la crisis de los socialismos reales, la globalización económica y el colapso de las narrativas emancipatorias modernas, los fundamentos de las democracias liberal-representativas comienzan a erosionarse, rutinizarse y subordinarse al predominio de otras lógicas de configuración social. En palabras de Capece (2009, p. 2), la des-democratización ha de ser entendida como el conjunto de "Procesos vinculados con el vaciamiento de lo político, de reducción política-ideológica que toma cuerpo en los denominados déficits de la democracia y su consecuente pesimismo sobre la democracia. Procesos de despolitización que se cristalizan en la pérdida de la credibilidad, representatividad, participación ciudadana y la inconformidad generalizada con el desempeño de las instituciones. Procesos y experiencias en las cuales se evidencia una falta de protección frente a acciones arbitrarias estatales y no estatales que debilitan la acción política de los ciudadanos. Situaciones de desigualdad extrema, tanto de recursos como de acceso al sistema político, en las cuales las condiciones básicas para la democratización están ausentes. Procesos de deterioro cualitativo en el que se van socavando lentamente las instituciones y los principios democráticos, prácticas de retraimiento de la dinámica democrática, tendencia a pasar de un "Estado social y democrático de derecho" a otro asistencial, neo-oligárquico y securitario. Atomización social, apatía política con raíz en problemas de acción colectiva; desmovilización y despolitización de actores colectivos". 
El segundo criterio se encuentra asociado al diagnóstico de los efectos que las transformaciones del capitalismo contemporáneo generan en las sociedades, efectos que básicamente se encuentran asociados con el debilitamiento de los lazos sociales, la precarización de la vida en general, la pérdida de centralidad del trabajo y la crisis del Estado y sus mecanismos de producción de integración social y sistémica.

Por último, el tercer criterio de contextualización se asocia con la categoría de "estado de excepción", un término ampliamente desarrollado desde el ámbito de la teoría política pero que, en este marco del debate, asume una característica precisa, asociada a lo que Durand (2010, p. 34) define del siguiente modo: “El concepto de Estado de excepción (...) se basa en las siguientes tres premisas: 1] la tesis benjaminiana, que parece inobjetable en las sociedades capitalistas: para los oprimidos se trata de un Estado de excepción permanente, el derecho siempre los desfavorece; 2] el Estado de derecho no se aplica en alguno de sus principios, o no es universal en los derechos fundamentales, o no realiza el equilibrio de poderes, o no garantiza la justicia para todos o no logra realizar ninguno; 3] el funcionamiento del orden burgués, capitalista en las sociedades periféricas, es siempre excepcional y por ende dificulta realizar la política".

La identificación de la ciudadanía precaria con la categoría de estado de excepción constituye un relevante indicio respecto a lo que, de modo más bien implícito, subyace a esta noción: la comprensión de la precariedad como un status ya no transitorio sino que permanente, en donde precisamente la excepción ha derivado en norma.

Ya sea como fruto de procesos que le imprimen a las democracias un sentido rutinizado y carente de ciudadanía, ya sea como resultado de las transformaciones contemporáneas del capitalismo o de la ampliación del "estado de excepción" como norma para el procesamiento de determinados problemas sociales, la noción de ciudadanía precaria se vincula en definitiva con la determinación de un contexto socio-histórico que, de modo más o menos intuitivo, se asume como divergente respecto a la trayectoria moderna. Constituiría, en este sentido, el nombre de un proceso de constitución de formas ciudadanas de pertenencia parcializada a la comunidad política para las cuales no existe un rumbo de incorporación o, dicho en otras palabras, formas precarias de incorporación al ejercicio de la ciudadanía.

\section{INMIGRACIÓN Y CIUDADANÍA PRECARIA}

En principio, la relación entre ciudadanía, Estado y nación puede ser asumida como impropia. Ideas tales como la centralidad del individuo, el privilegio de 
la racionalidad como instrumento privilegiado a la hora de constituir un orden político, la exclusión de la tradición del terreno político-público y el carácter des-fundamentado del mismo, entre otros aspectos constitutivos de la gramática ciudadanista, resultan en principio fuertemente antagónicos frente a una categoría que, como la de nación, supondría la existencia de una "comunidad solidaria", un espacio pre-político de delimitación de la pertenencia a un cuerpo colectivo que establece de modo a-priori los límites de la misma comunidad. Y sin embargo, el vínculo entre la tradición política moderna y la idea de Nación no sólo ha existido, sino que ha representado una de las articulaciones más relevantes en lo que refiere a la constitución de los sistemas democráticorepresentativos actualmente vigentes a escala global.

Esta aparente discordancia nos sitúa frente a un problema teórico-conceptual que ha intentado ser encarado de distintas maneras: si la idea de nación se entiende como un dispositivo que opera en base a una "ficción de homogeneidad cultural" (Palti, 2006, p. 29) o, como plantea Habermas (1999, p.19), en la forma de un "resto no secularizado de trascendencia", su articulación con el concepto de ciudadanía resulta en principio, a lo menos, digna de ser puesta en cuestión. Y es que, ¿cómo hacer compatible un principio pre-político de homogeneidad con el status de pertenencia a una comunidad política?; ¿de qué modo armonizar la naturaleza eminentemente política del concepto de ciudadanía con un residuo comunitario de trascendencia no secular?

Pues bien, la expresión más clara de esta tensión entre ciudadanía y pertenencia nacional es la que opera como telón de fondo de los procesos migratorios, procesos en los cuales esta vinculación aporética se ve expuesta de modo claro. Y es que, tal y como lo señala Velasco (2016, p. 16), “La nacionalidad tal vez sea actualmente el criterio legal más importante para la asignación no solo de derechos y obligaciones, sino de bienes y servicios. Simultáneamente sirve como uno de los últimos criterios de discriminación legal. Que sea lo habitual no significa, sin embargo, que resulte aceptable. Que el documento de nacionalidad que uno porte determine las expectativas vitales resulta tan injusto como que lo haga la extracción social, la filiación religiosa o el color de la piel, criterios todos ellos que han quedado desacreditados. Nadie elige el lugar de su nacimiento y, por lo tanto, nadie puede responder por ello. Tampoco nadie, en consecuencia, lo debería esgrimir en su favor".

¿Cómo explicar este vínculo aporético entre ciudadanía y pertenencia nacional? Las interpretaciones respecto a esto se han dirigido, en el campo del teoría social y política, por el camino de la constatación de una necesidad típicamente moderna de consolidación de formas renovadas de legitimación e integración social que fueran capaces de soportar la disolución de las formas tradicionales de cohesión social. La Nación, de esta forma, fundaba una 
necesaria al mismo tiempo que artificiosa modalidad de integración y homogeneización capaz de generar las condiciones para el desenvolvimiento de la ciudadanía moderna. Y es que, en definitiva, " $[. .$.$] a esta transforma-$ ción jurídico-política le hubiera faltado la fuerza motriz y la república formalmente establecida hubiera carecido de la fuerza vital si el pueblo [...] no se hubiera convertido, de acuerdo con su propia autocomprensión, en una nación de ciudadanos conscientes de sí mismos. Para lograr esta movilización política se precisaba una idea con fuerza capaz de crear convicciones y de apelar al corazón y al alma de una manera más enérgica que las ideas de soberanía popular y derechos humanos. Este hueco lo cubre la idea de nación" (Habermas, 1988, p. 89).

De esta manera es como, si el reconocimiento de derechos inalienables y universales constituye el principio formal básico de la constitución de la noción moderna del ciudadano, su adscripción nacional cumpliría con cubrir el déficit de integración presente en este reconocimiento. Es decir, ciudadanía y nación formarían una articulación por medio de la cual la idea misma de nación incorpora un elemento que vuelve concreta, aprehensible y funcional la universalidad abstracta contenida en el principio liberal de los "derechos universales del hombre y del ciudadano".

Tal y como señala Zuñiga (2010, p. 136), en definitiva, "el desarrollo del Estado moderno como un Estado nacional, y la necesidad de dotar al discurso iusfundamental de una eficacia jurídica que solo es posible garantizar a través de la producción normativa estatal, terminarán circunscribiendo la universalidad a las fronteras nacionales".

Pues bien, es precisamente esta vinculación entre ciudadanía y pertenencia nacional la que permite el establecimiento de un claro vínculo entre las poblaciones migrantes y la noción más arriba desarrollada de ciudadanía precaria. Resulta evidente, en este sentido, la proximidad de los individuos y grupos asociados a esta condición precaria de la ciudadanía con las condiciones fácticas en las que operan los procesos de incorporación de los y las inmigrantes en sus respectivas sociedades receptoras, por lo que la presencia de referencias a esta noción de ciudadanía precaria como estrategia de caracterización de la condición migrante resulta una cuestión claramente esperable.

Thayer y Stang (2016, p.15), por ejemplo, proponen la categoría de "estatus legal precario" para dar cuenta de situaciones en la que la precariedad "no es un estado necesariamente transitorio, sino una condición que puede perpetuarse en las trayectorias migratorias". Munck (2013, p. 44), por su parte, vincula la noción de ciudadanía precaria con la de precariado laboral, señalando que "el trabajo precario es acompañado, con mayor frecuencia, de 
una forma igualmente precaria de ciudadanía para la mayoría de los migrantes"

De acuerdo a estas asociaciones, las condiciones de acceso de la población migrante al mercado laboral, adicionada a su difícil articulación con el movimiento sindical y las prácticas reivindicativas en general de los países receptores, generan condiciones estructurales que impiden su plena incorporación a la comunidad política, produciendo por consecuencia la solidificación de una condición de ejercicio precario de los derechos ciudadanos.

Las diversas formas de discriminación, el establecimiento de excepcionalidades y condicionamientos reglamentarios, las interacciones propias de la relación entre los migrantes y la población e institucionalidad de los países receptores, en este sentido, constituyen fuentes relevantes de atención para la determinación de las referidas formas precarias de ejercicio de la ciudadanía, fuentes que por cierto han sido objeto de una amplia producción investigativa en el campo de los estudios sobre migración.

La condición ciudadana precaria, en definitiva, tendría una clara expresión en las formas de incorporación de los individuos, poblaciones y colectivos migrantes. Una expresión que adquiere un singular sentido e intensidad dada la referida desvinculación con la pertenencia nacional que los caracteriza.

\section{LA "CIUDADANÍA PRECARIA" COMO CONCEPTO: UNA PROPUESTA}

Al igual como ocurre con gran parte de los significantes utilizados en el campo de los estudios sociales, la noción de "ciudadanía precaria" emerge como efecto más de un acto político que de una necesidad epistemológico-cognoscitiva. Y es que, tal y como lo señala Laclau (2005, p. 132) en referencia al enfoque antidescriptivista, existen definiciones que son más el efecto de un "bautismo originario" que de un esfuerzo descriptivo por caracterizar atributos posibles de aprehender a un determinado objeto.

Este tipo de definiciones, expresivas del hecho que "la lógica de la conceptualización o del lenguaje mismo no puede separarse de la política" (Marchart, 2009 , p. 85), se caracterizan por encarnar un efecto de intervención sobre aquello que se "describe". Es así como, refiriendo directamente a nuestro caso, las alusiones a la noción de ciudadanía precaria más arrbia referidas no pueden ser separadas de una disposición crítica respecto a la forma en que algunos individuos, grupos o poblaciones han sido desalineados total o parcialmente del status ciudadano. La adición del atributo "precario" a ciertas formas ciu- 
dadanas constituye, en este sentido, una nominación lógicamente anterior a toda mediación conceptual de atribución de significado a una palabra. De modo contrario a las concepciones típicamente descriptivistas del lenguaje según las cuales "la función del significante no sería más que representar el significado de éstos" (Rodriguez, 2010, p. 9), la imputación a ciertas expresiones de la ciudadanía del atributo "precario" contiene una carga nominativa originaria que se sobrepone a la operación pretendidamente ascéptica que suelen contener las estrategias de definición conceptual y que se dirije, de modo más o menos explícito, por la vía de la intervención sobre aquella realidad que se nomina.

En el caso de los colectivos migrantes, esta carga nominativa adquiere una particular intensidad dada su referencialidad cada vez más frecuente en los espacios de disputa política nacional. El surgimiento de diversas expresiones que antagonizan con porciones o con el conjunto de las poblaciones migrantes, y que convierten este tópico en un clivaje relevante para la política de los paises receptores, otorga un fuerte sentido al desplazamiento metonímico por medio del cual la noción de precariedad se articula con el conjunto de personas migrantes. Referir a estas personas, poblaciones o colectivos como "ciudadanos precarios" contiene, por consecuencia, una connotación primigeniamente política antes que conceptual o terminológica. Dicho en otras palabras, la "ciudadanía precaria" se configura en cuanto nombre de un diagnóstico y una demanda: el diagnóstico de una situación de injusticia, y la demanda de la reparación de dicha situación. Constituye en definitiva, y haciendo uso de la distinción que Palti (2005) propone en relación al pensamiento marxista, mucho más una "verdad" que un "saber".

Ahora bien, ¿significa esto que la nominación "ciudadano precario" no presenta un valor que pueda trascender a su sentido político?; ¿el reconocimiento del carácter primariamente nominativo antes que categorial de esta definición anula su potencialidad conceptual? Sobre esto, estimamos que la comprensión del nombre "ciudadanía precaria" desde una perspectiva antidescriptvista no implica necesariamente que ésta no tenga la capacidad de convertirse en una definición conceptual posible de ser utilizada para la caracterización de los procesos de incorporación de las poblaciones migrantes. Por el contrario, pensamos que dicha definición contiene una fuerte potencialidad puesto que da cuenta de la naturaleza indeterminada de procesos de incorporación/exclusión caractarizados por su parcialidad y la incompletitud. Indeterminación, pues la deriva de los procesos de incorporación siempre es incierta, y se encuentra sometida a dinámicas contingentes imposibles de ser prediseñadas; parcialidad, por cuanto la adquisición de derechos ciudadanos por parte de los individuos y colectivos migrantes siempre opera de forma parcial o, en el mejor de los casos, progresiva; incompletitud, pues la condición de extranjería 
opera siempre como indicador de la participación parcial en la comunidad política. Ubicada en el intersticio de la condición de plena ciudadanía o de plena exterioridad, estos atributos constituyen por consecuencia una aproximación adecuada a la naturaleza misma de los procesos migratorios.

Ahora bien, ¿cómo convertir este nombre en una definición conceptual? Tal y como lo señalamos más arriba, las referencias a la noción de categoría precaria aluden a tres dominios dentro de los cuales esta definición se expresaría: un dominio que llamaremos normativo, vinculado a la forma en que los estados procesan legalmente la relación con determinados colectivos; un segundo que denominaremos como político, asociado al conjunto de políticas que el Estado ejecuta (o no) en los distintos planos de la vida social en relación a determinados individuos o grupos sociales; y un tercer dominio, de carácter interactivo, referido a las dinámicas de interacción sociopolítica entre el espacio social en general, el Estado y grupos sociales específicos.

Cada uno de los dominios señalados conduce a ambitos y atributos en los cuales se expresaría la condición precaria del ejercicio ciudadano, los que en la literatura revisada son indicados con diferentes frecuencias e intensidad variable. En los usos de este nombre para la caracterización de los procesos de incorporación migratoria ocurre lo mismo, siendo posible rastrear la presencia de un conjunto de ámbitos de observación asociados a los dominos ya nombrados.

\begin{tabular}{|c|c|c|}
\hline Dominio & Ambitos & Atributos distintivos \\
\hline Normativo & $\begin{array}{l}\text { - } \quad \text { Legislación migratoria } \\
\text { - } \quad \text { Categorías migratorias legales }\end{array}$ & $\begin{array}{l}\text { - Legislación que limita/restringue/discrimina } \\
\text { o condiciona el acceso ciudadano } \\
\text { - ausencia de legislación migratoria. }\end{array}$ \\
\hline Político & $\begin{array}{l}\text { - Políticas de ingreso y expulsión } \\
\text { - Condicionamiento del acceso a } \\
\text { derechos } \\
\text { - Acceso a bienes públicos }\end{array}$ & $\begin{array}{l}\text { - Ausencia de política efectiva hacia migrantes } \\
\text { - Presencia de políticas ambiguas, discre- } \\
\text { cionales y/o discontinuas } \\
\text { - Presencia de una política explícitamente } \\
\text { segregadora y/o excluyente. }\end{array}$ \\
\hline Interaccional & $\begin{array}{l}\text { - } \text { Discursos públicos } \\
\text { - Representaciones sociales y } \\
\text { racismo } \\
\text { - Politización población migrante }\end{array}$ & $\begin{array}{l}\text { - Representaciones sociales excluyentes hacia } \\
\text { grupos o la totalidad de la población migrante. } \\
\text { - Discursos políticos y disposición excluyente } \\
\text { de las actorías políticas frente a la inigración. } \\
\text { - Bajos o inexistentes niveles de politicidad de la } \\
\text { población migrante. } \\
\text { - Acción colectiva de corte peticionario. }\end{array}$ \\
\hline
\end{tabular}

Dominios y atributos de la "Ciudadanía precaria migrante". Elaboración propia 
Ahora bien, ¿de qué forma se vinculan estos atributos?; ¿cuál es el peso relativo de cada uno de sus dominios en la determinación de la presencia o ausencia del status precario en un determinado colectivo migrante? Kurt Weyland, en un clásico trabajo referido a las variadas estrategias de conceptualización del significante "populismo" (2004), propone una distinción entre formas aditivas y acumulativos de elaboración conceptual. Mientras las primeras implican la elaboración de una categoría a partir de una sumatoria simple de atributos caracterizada en la utilización preferente del conectivo lógico "o", las conceptualizaciones de tipo acumulativas se fundan en el imperativo de agregar atributos pero ahora bajo la utilización del conectivo lógico " $y$ ", es decir, definiendo a un determinado objeto como conformado por la confluencia necesaria de un conjunto de atributos.

Para nuestro caso, esta distinción nos conduce a la pregunta relativa al vínculo que, en las distintas definiciones observadas, existe entre los dominios que participan de la construcción de la definición "ciudadanía precaria". ¿ ¿constituye la presencia de los tres dominios arriba descritos una condición necesaria o, por el contrario, basta con la manifestación de solo alguno de ellos para la imputación de un colectivo como afectado por una condición ciudadana precaria?; ¿estas definiciones se aproximan más a lo que se entiende como un concepto aditivo de carácter laxo o, por el contrario, un concepto acumulativo de corte más exigente y exclusivo?

La revisión de la literatura referida a la noción de ciudadanía precaria nos permite asumir la presencia de estrategias de definición de carácter aditivo. La incorporación de atributos pertenecientes a todos y cada uno de los dominios identificados -normativo, político e interaccional- no emerge en estas definiciones como una condición necesaria para la construcción de una definición que, en definitiva, opera más bien como la sumatoria simple, no exhaustiva y en ningún caso imperativa de un conjunto de rasgos que no necesariamente provienen de los tres dominios identificados.

Este primado de la lógica aditiva en la definición de la ciudadanía precaria deriva según nuestro juicio en la producción de una definición inespecífica, carente de rigurosidad y expresiva del clásico problema del estiramiento conceptual, noción según la cual la adición simple de atributos como estrategia para la definición de una determinada categoría redunda en "un concepto poco ambicioso y académicamente pobre” (Sansó-Rubert, 2011, p. 163).

Si la noción de ciudadanía precaria aplica para formas y contextos ampliamente diversos, ello conlleva el riesgo -a nuestro juicio efectivo- de la disolución de su especificidad y, por consecuencia, de su conversión en una definición improbable de ser asumida en tanto concepto capaz de dar cuenta de algún 
aspecto específico del ejercicio de la ciudadanía o, en el mejor de los casos y tal como señala Rodríguez (2018, p.69), una definición que "se asemeja a un continuum, donde algunas personas tienen un rango más limitado de derechos que otros y otras ni siquiera alcanzan este umbral".

El problema de lo arriba expuesto es que el acceso diferenciado, desigual y problemático a la ciudadanía ha sido, tal y como lo hemos señalado en los apartados anteriores, una constante desde el advenimiento mismo de la modernidad y constituye, por consecuencia, más una norma en toda definición de ciudadanía que la indicación de una modalidad específica y diferenciada respecto a la cual la noción de ciudadanía precaria pudiera dar cuenta. En otras palabras: una estrategia de definición aditiva de ciudadanía precaria nos conduciría por la ruta de su identificación, sin más, con las formas efectivas de ejercicio de la ciudadanía.

¿Cómo resolver esta naturaleza inespecífica que impide la conversión de las definiciones de ciudadanía precaria en un concepto que permita observar la dinámica efectiva de los procesos de ciudadanización/desciudadanización de los colectivos migrantes? A nuestro juicio, una estrategia posible para la conversión del nombre "ciudadanía precaria" en un concepto eficiente pasa necesariamente por un doble ejercicio de 1) vinculación de los dominios identificados en una fórmula de tipo acumulativa e 2) inscripción de la definición en un marco contextual específico.

Respecto a lo primero, la naturaleza ambigua e indeterminada que contiene la definición moderna de "ciudadanía" obliga a que la construcción de una definición de "ciudadanía precaria" avance sustantivamente en su nivel de especificidad y delimitación, de modo tal de volverse una categoría con valor heurístico y con una diferencia específica posible de ser verificada por medio de la indagación en las formas de inclusión/exclusión de colectivos sociales específicos. En este sentido, el carácter más exigente que caracteriza a un concepto de tipo acumulativo -que asume la necesaria presencia del conjunto de dominios que forman parte de su definición- permite la construcción de un concepto con mayor capacidad descriptiva y explicativa.

En segundo lugar, y tal como ha sido descrito en el apartado anterior, la inscripción de la definición que nos ocupa en el contexto socio-histórico de crisis del Estado moderno y de las instituciones democráticas, de profundización de los efectos de la globalización y de modificación de las formas de organización del capitalismo contemporáneo abre paso a una temporalidad descrita en las distintas definiciones respecto a la ciudadanía precaria- que proponemos asumir como constitutiva de toda estrategia de definición conceptual de esta categoría. 
En síntesis, las posibilidades de construcción de una definición conceptual de la "ciudadanía precaria" capaz de aportar eficazmente a los procesos contemporáneos de incorporación/ exclusión de los individuos, poblaciones y colectivos migrantes requieren de la producción de una definición altamente exigente (como la que ofrecen las conceptualizaciones de tipo acumulativo) y fuertemente inscrita en el contexto socio-histórico contemporáneo. Solo así, estimamos, esta definición alcanzará su diferencia específica respecto a la categoría ciudadanía, y podrá constituirse en un instrumento conceptualmente valioso.

\section{CONCLUSIONES}

La relación entre ciudadanía, migración y nacionalidad constituye un problema de creciente atención en el campo de las ciencias sociales. ¿Cuál es la relación entre ambos términos?; ¿de qué manera las poblaciones migrantes se vinculan con las comunidades receptoras y de qué forma operan sus procesos de ciudadanización?

Estas preguntas han sido abordadas a partir de distintas estrategias, una de las cuales ha sido la del uso de la definición "ciudadanía precaria" como una forma de caracterización de la naturaleza de los procesos de incorporación de los individuos, poblaciones y colectivos migrantes en sus respectivas comunidades políticas receptoras. Usada como una definición que permite la identificación de individuos y grupos afectados por formas de exclusión, segregación o desconocimiento, la "ciudadanía precaria" ha operado más como un acto nominativo de demanda y denuncia de la condición incompleta con que algunos sujetos sociales se relacionan con sus respectivas comunidades políticas que como una definición conceptual capaz de determinar una diferencia específica respecto a la categoría genérica de ciudadanía.

Considerando lo arriba expuesto es que, en este ensayo, nos propusimos aportar elementos para la producción de una definición conceptual de la noción "ciudadanía precaria". Reconociendo el valor de su sentido nominativo, intentamos argumentar acerca de la necesidad de producción de un concepto de carácter acumulativo configurado por tres dominios -normativo, político e interactivo- capaces de identificar de modo exhaustivo las modalidades de incorporación precaria de los individuos, poblaciones y colectivos migrantes a la ciudadanía.

La producción de un concepto dotado de dominios y atributos claramente definidos que permita caracterizar de modo claro y preciso la naturaleza precaria de los procesos de ciudadanización migrantes, asumimos, aporta no solo al conocimiento de dichos procesos sino que además, y con especial énfasis, al 
debate en torno a los mecanismos más eficientes para su plena incorporación a la comunidad política.

\section{REFERENCIAS}

Baños, O. (2015). Percepciones juveniles de ciudadanía. El caso de Yucatán. Península, X(1), 95-120. doi:doi.org/10.1016/j.pnsla.2014.08.002

Bobes, V. (2004). Cudadanía. En L. B. (eds.), Léxico de la polítca. Cudad de México: FLACSO.

Bobes, V. (2007). La nación inconclusa. (Re) constituciones de la ciudadanía y la identidad nacional en Cuba. Ciudad de México: FLACSO.

Bovero, M. (2002). Una gramática de la democracia. Contra el gobierno de los peores. Madrid: Trotta.

Capece, E. (s.f). América Latina: acontecimiento y democracia a comienzos del siglo XXI. XXIX congreso ALAS, (pág. s/p). Buenos Aires. Obtenido de http:// actacientifica.servicioit.cl/biblioteca/gt/GT20/GT20_CapeceWoronowicz.pdf

Celorio, M. (2017). Violencia biopolítica contra poblacions de la diversidad sexual: homofobia, derechos humanos y ciudadanía precaria. El cotidiano(202), 17-29. Obtenido de http:/ / www.redalyc.org/articulo.oa?id=32550024003

Durand, V. (2010). Desigualdad social y ciudadanía precaria ¿Estado de excepción permanente? Ciudad de México: UNAM.

Habermas, J. 1998. Facticidad y validez. Sobre el derecho y el estado de derecho en términos de teoría del discurso. Madrid: Trotta.

Habermas, J. (1999). La inclusión del otro. Estudios de teoría política. Barcelona: Paidós.

Huntington, S. (2004). ¿Quiénes somos? Barcelona: Paidos.

Laclau, E. (2005). La razón populista. Buenos Aires: FCE.

Macpherson, C. (1997). La democracia liberal y su época. Madrid: Alianza.

Marchart, O. (2009). El pensamiento político postfundacional. La diferencia política en Nancy, Lefort, Badiou y Laclau. Buenos Aires: FCE.

Mill, J. S. (1994). Del gobierno Representativo. Madrid: Tecnos. 
Molina, J. (2014). Aportes para pensar la ciudadanía. Por una crítica a su concepción convencional. Administración \& Desarrollo, 43(59), 87-98. doi:10.22431/ 25005227.107

Moreno, L. (2010). Ciudadanos precarios. La última red de protección social. Barcelona: Ariel.

Munck, R. (2013). ¿Más allá del norte y del sur? Migración, informalización y revitalización sindical. Migración y desarrollo, 11(20), 43-66. Obtenido de http:// www.redalyc.org/articulo.oa?id=66028343003

Oxhorn, P. (2014). La sociedad civil de adentro hacia afuera. Comunidad, organización y desafío de la influencia política. Revista Mexicana de Ciencias Políticas y Sociales, LIX(222), 257-278. doi:10.1016/S0185-1918(14)70218-1.

Palti, E. (2006). La nación como problema. Los historiadores y la "cuestión nacional". Buenos Aires: FCE.

Rial, P. R. (2001). Diccionario Akal de Filosofía. Madrid: Akal.

Rodríguez, G. (2018). Ciudadanía y mundo del trabajo: “ ¿Vivir en la incertidumbre y disfrutarla?». Cartografías de la nueva ciudadanía. Documento de trabajo 81. Buenos Aires: Instituto de investigaciones Gino Germani.

Rodriguez, L. (2010). La tensión entre ciencia e ideología: contribuciones de las teorías contemporáneas del sujeto al debate epistemológico. VI Jornadas de Sociología de la UNLP (págs. 1-32). la Plata: UNLP.

Rubio, J. (2007). Teoría crítica de la ciudadanía democrática. Madrid: Trotta.

Sansó-Rubert, D. (2011). Criminalidad organizada transnacional en Asia-Pacífico: repercusiones para la seguridad. UNISCI Discussion Papers, 159-190. Obtenido de http:/ / www.redalyc.org/articulo.oa?id=76718800008

Thayer, L. E. y Stang, F. (2016). Estatus legal precario y condicionalidad en el acceso a derechos. Una aproximación a la regulación migratoria de Argentina y canadá. Si Somos Americanos. Revista de Estudios Transfronterizos., 16(2), 11-43. doi:http:// dx.doi.org/10.4067/S0719-09482016000200001.

Velasco, J. C. (2016). El azar de las fronteras. Pol'tcas migratorias, ciudadanía y justicia. Ciudad de México: FCE.

Vite, M. (2012). La discapacidad en México desde la vulnerabilidad social. Polis, 8(2), 153-173. Obtenido de http:// www.scielo.org.mx/pdf/polis/v8n2/v8n2a6.pdf 
Weyland, K. (2004). Clarificando un concepto cuestionado: el populismo en el estudio de la política latinoamericana. En C. d. Gerardo Aboy, Releer los populismos. Quito: CAAP.

Zapata, R. (2001). Cudadanía democrática y pluralismo cultural: hacia un nuevo contrato social. Barcelona: Anthropos.

Zuñiga, Y. (2010). Ciudadanía y Género. Representaciones y conceptualizaciones en el pensmaineto moderno y contemporáneo. Revista de Derecho Universidad Católica del Norte, 17(2), 133-163. Obtenido de http:/ / revistaderecho.ucn.cl/article/view/ 2078 
